\title{
O FUNCIONAMENTO SEMÂNTICO-ARGUMENTATIVO DA MODALIZAÇÃO EPISTÊMICA QUASE-ASSEVERATIVA
}

\section{THE SEMANTIC-ARGUMENTATIVE FUNCTIONING OF THE ALMOST-ASSEVERATIVE EPISTEMIC MODALIZATION}

\author{
Francisca Janete da Silva Adelino - UFPB ${ }^{1}$ \\ Erivaldo Pereira do Nascimento - UFPB ${ }^{2}$
}

\begin{abstract}
RESUMO
O presente artigo discute o funcionamento semântico-argumentativo da modalização epistêmica quase-asseverativa na construção argumentativa do gênero entrevista de seleção de emprego. Pretendemos saber (i) que recursos linguísticos instauram a modalização quase-asseverativa em entrevistas de seleção de emprego; e (ii) como esses recursos funcionam estrategicamente para gerar orientação argumentativa durante o processo interativo no gênero em estudo. Para tanto, adotamos os pressupostos da semântica argumentativa de Ducrot (1988); juntamente com os estudos da modalização desenvolvidos por Lyons (1977); Cervoni (1989); Castilho e Castilho (1993); Palmer (2001); Neves (2011); Nascimento (2010); Nascimento e Silva (2012); além de outros estudiosos dessa área. A pesquisa assume uma abordagem qualitativa e um caráter descritivo de base interpretativa, já que identificamos e interpretamos os modalizadores epistêmicos quase-asseverativo presentes no corpus, atentando para o seu funcionamento argumentativo. O corpus é constituído por vinte e duas entrevistas de seleção de emprego gravadas e coletadas em um Centro Universitário localizado em Natal-RN. As análises revelam que, ao fazer uso desse subtipo de modalizador, o entrevistado e o entrevistador demonstram certo distanciamento em relação ao que apresentam em seus discursos. Ademais, esse distanciamento fica marcado pela atenuação impressa no conteúdo da proposição, pela relativização da força da asserção e também pela isenção da responsabilidade com o dito. Além disso, ao usar esse recurso, os locutores não se comprometem com o conteúdo enunciado e, assim, apresentam a proposição em forma de hipótese que depende de confirmação.
\end{abstract}

PALAVRAS-CHAVE: Modalização; Argumentação; Entrevista de seleção de emprego.

\section{ABSTRACT}

This article discusses the semantic-argumentative functioning of the almost-asseverative epistemic modalization in the argumentative construction of the job interview genre. We intend to know (i) what linguistic resources introduce the almost-asseverative modalization in the job interview genre; and (ii) how these resources work strategically to generate argumentative orientation during the interactive process in the studied genre. We adopted the theoretical frame of the Argumentative Semantics by Ducrot (1988); together with the studies of the Modalization that were developed by Lyons (1977); Cervoni (1989); Castilho and Castilho (1993); Palmer (2001); Neves (2011); Nascimento (2010); Nascimento and Silva (2012); and other scholars in this field. The research assumes a qualitative approach and a descriptive nature of the interpretative basis, considering that we identify and interpret the almost-asseverative epistemic modalizers in the corpus, paying attention to its argumentative functioning. The corpus is comprised of twenty-two job interview genres recorded and collected at a University Center located in Natal-RN. The analyses reveal that, the use of this subtype of modalizer, the

\footnotetext{
1 Professora Dra. do Departamento de Ciências Sociais Aplicadas da UFPB janete adelino@hotmail.com

2 Professor Dr. do Departamento de Letras da UFPB erypn@hotmail.com
} 
interviewee and the interviewer demonstrate a certain distance in relation to what they present in their speeches. In addition, this distance is marked by the printed attenuation in the content of the proposition, by the relativization of the assertion force and also by the exemption of the responsibility with what was said. Besides that, when using this resource, the locutors do not commit to the said content, and so, they present the proposition in the form of a hypothesis that depends on the confirmation.

KEYWORDS: Modalization; Argumentation; Job interview genre.

\section{INTRODUÇÃO}

O presente trabalho discute o funcionamento semântico-argumentativo da modalização epistêmica quase-asseverativa na construção argumentativa do gênero entrevista de seleção de emprego. Pretendemos, principalmente desvendar (i) que recursos linguísticos instauram a modalização quase-asseverativa em entrevistas de seleção de emprego; e (ii) como esses recursos funcionam estrategicamente para gerar orientação argumentativa durante o processo interativo no gênero em estudo. As entrevistas examinadas fazem parte do universo empresarial e são utilizadas, principalmente, por profissionais da área de Recursos Humanos para aprofundar questões relacionadas às competências e habilidades de candidatos à vaga de emprego, em processos de recrutamento e seleção de pessoal, conforme comenta Adelino (2016).

A Teoria da Argumentação na Língua (TAL) de Ducrot (1988); juntamente com os estudos da modalização desenvolvidos por diversos pesquisadores, dentre eles Castilho e Castilho (2002); Neves (2011); Nascimento (2010); Nascimento e Silva (2012); entre outros, representam a base teórica deste trabalho. As pesquisas desses estudiosos têm servido de base para ancorar diversas investigações cujo propósito é discutir a argumentação como fator essencial para a compreensão do sentido do enunciado. Algumas dessas investigações, depositadas no campo da Linguística, têm contribuído principalmente para ampliar o entendimento a respeito do funcionamento da língua não apenas como estrutura, mas também enquanto prática social de interação verbal e, portanto, procura estudar como o falante usa a língua interativamente nas mais diversas esferas sociais.

Em diálogo com a TAL, a seguir, apresentamos alguns conceitos acerca da modalização, focando principalmente na categoria epistêmica quase-asseverativa. $\mathrm{Na}$ sequência, após apresentarmos os aspectos metodológicos da pesquisa, analisaremos os dados coletados do corpus e discutiremos os resultados alcançados. Por fim, apresentaremos algumas considerações sobre os resultados obtidos.

\section{Argumentação na língua e modalização: algumas considerações}

A argumentação, para Ducrot (1988), está inscrita na língua e encontra-se marcada nas escolhas linguísticas que o locutor faz ao apresentar um enunciado. A grande importância dessa teoria para o desenvolvimento dos estudos linguísticos está em colocar a língua no centro da questão argumentativa, ou seja, a argumentação não deriva de condições de verdade, e sim está inscrita na própria língua. E a língua, por sua vez, oferece ao usuário uma infinidade de possibilidades de construção e também uma série de limitações de uso.

Espíndola (2003), ao analisar a TAL, acrescenta que não apenas a língua é por natureza argumentativa, bem como o uso que dela fazemos nas nossas situações e ações de interações sociais.

Assim, entre as diferentes possibilidades, a língua oferece aos interlocutores um conjunto de recursos que se apresenta ao falante como possibilidades diversas de uso, de estratégias, de jogos de que ele pode dispor para cumprir seu propósito comunicativo. Dentre essas possibilidades, temos os modalizadores, que materializam a modalização discursiva, aqui 
considerada como um fenômeno semântico-argumentativo e pragmático através do qual o locutor deixa registrado, no seu discurso, marcas de sua subjetividade e, portanto, transmite o modo como esse discurso deve ser lido. É para esse fenômeno que voltamos nossa atenção agora. Vale ressaltar que é visando atender aos objetivos da nossa pesquisa que, de forma mais minuciosa, discorremos acerca da modalização, focando os tipos de modalizadores categorizados pelos estudos já realizados sobre o assunto.

Assim, os estudos linguísticos da modalização estão vinculados aos estudos lógicos. Portanto, o conceito de modalidade não é novo e nem exclusivo da linguística. Além disso, existe um entendimento diversificado quanto a essa noção, o que exige de nós certa cautela ao percorrermos os escritos que versam sobre esse assunto.

A lógica clássica é apontada por estudiosos da modalidade como a primeira área a utilizar tal noção, isso em termos históricos. É entre os gregos que temos o primeiro registro de uma concepção de modalidade (CERVONI, 1989). No entanto, esse termo também é mobilizado pelos linguistas, mais precisamente - mas não exclusivamente - pelos estudiosos do campo da semântica argumentativa. Cervoni (1989, p. 54) registra que "[...] é preciso lembrar que o conceito de modalidade pertence tanto aos linguistas quanto aos lógicos, mas que os lógicos foram os primeiros a elaborá-lo e que ele permanece um de seus conceitos fundamentais".

Em sua proposta de estudo, Cervoni (1989) postula que tal conceito assume, na linguística, características próprias, uma vez que os estudos linguísticos vão se preocupar com os aspectos sintáticos, morfológicos, fonológicos, semânticos e pragmáticos do uso da modalidade.

Nascimento (2009) conceitua a modalização ou modalidade como uma estratégia argumentativa $^{3}$ que permite ao locutor, responsável pelo discurso, imprimir no enunciado uma avaliação ou ponto de vista sobre o conteúdo de sua enunciação ou sobre a própria enunciação. Essa concepção do fenômeno da modalização é desenvolvida por outros estudiosos da área, entre os quais Castilho e Castilho (2002), Koch (2011) e o próprio Nascimento (2005), que têm uma concepção mais semântico-discursiva ou semântico-pragmática a respeito do fenômeno.

Castilho e Castilho (2002) ao analisarem o funcionamento dos advérbios modalizadores como recursos que marcam as expectativas do locutor sobre o conteúdo da proposição, organizaram um quadro com três tipos de modalização: modalização epistêmica; modalização deôntica e modalização afetiva. Algumas dessas se desdobram em subcategorias, como a modalização epistêmica quase-asseverativa que veremos no decorrer desta discussão.

Por sua vez, Neves (2011, p. 159) retoma as noções de "necessidade" e "possibilidade" que estão na base das modalidades para dizer que essas noções "se resolvem em subcategorias modais (alética/epistêmica/deôntica/bulomaica/disposicional)". Ao reconhecer a diversidade de tipos de modalidades existentes nos mais diversos trabalhos da área de linguística, Neves (2011, p. 162) entende que elas podem ser resumidas "[...] na distinção genética entre modalidade epistêmica e não-epistêmica (de raiz: deôntica e dinâmica)". Assim, a autora mostra que os estudiosos da área apresentam distinções quanto à bipartição entre as modalidades.

Considerando o objetivo deste artigo, faremos, a seguir, uma resenha de alguns dos principais conceitos da modalização epistêmica, sobretudo sobre o subtipo epistêmico quaseasseverativo.

\footnotetext{
${ }^{3} \mathrm{~A}$ noção de argumentação que trabalhamos é a perspectiva de Ducrot e colaboradores (1988) segundo a qual a língua é por natureza argumentativa, juntamente com o acréscimo proposto por Espíndola (2004) no qual a autora afirma que não só a língua é por natureza argumentativa, como também o uso que dela fazemos nas nossas interações sociais.
} 


\subsection{Modalização epistêmica}

A modalidade epistêmica, de acordo com Lyons (1977), está relacionada ao conhecimento ou crença do falante em relação à verdade de uma proposição. Dessa forma, um enunciado epistemicamente modalizado é aquele em que o falante qualifica explicitamente seu comprometimento com relação à verdade da proposição.

$\mathrm{Na}$ visão de Palmer (2001), esta modalidade indica o grau de comprometimento do falante no que diz respeito à evidência ou fonte do que se diz, assim como os julgamentos, opiniões ou conclusões do falante.

Nessa mesma perspectiva, Castilho e Castilho (2002) asseveram que esse tipo de modalidade ocorre quando o falante expressa uma avaliação sobre o valor de verdade e as condições de verdade da proposição. Esses autores mostram como alguns advérbios e expressões adverbiais são suscetíveis de veicular uma avaliação do falante sobre as significações contidas na proposição.

A respeito dessa modalidade, Neves (2011), por sua vez, também dedicou atenção à modalização epistêmica. Inicialmente ela situa essa modalidade como estando relacionada com a necessidade e a possibilidade epistêmicas. Essas modalidades dependem, segundo a autora, de como o mundo é. Além do mais, esse tipo de modalidade traz à tona os conhecimentos que o falante tem sobre o mundo, sendo esse conhecimento representável por meio de um conjunto de proposições. A autora explica: "Uma proposição $p$ é epistemicamente necessária se $p$ for acarretada por aquilo que o falante sabe sobre o mundo, e uma proposição $p$ é epistemicamente possível se $p$ for compatível com aquilo que o falante sabe sobre o mundo" (NEVES, 2011, p. 160).

Ainda de acordo com Neves (2011), embora o uso da modalização epistêmica esteja relacionado com a fonte do conhecimento, o falante pode não estar comprometido com tal conhecimento. Desse modo, conhecer a fonte do conhecimento é conhecer a própria informação ou pelo menos a origem dela. "Essa informação epistêmica é definida como a qualificação da informação em termos de sua origem ou da própria atitude do falante (crença, dúvida, etc.)", explica Neves (2011, p. 164).

\subsection{A modalização epistêmica quase-asseverativa}

Os modalizadores quase-asseverativos são conceituados em relação aos asseverativos, tendo em vista que, enquanto nos asseverativos temos uma certeza, um envolvimento do locutor sobre o conteúdo da proposição, nos quase-asseverativos o conteúdo da proposição é apresentado como uma crença, ou seja, temos nesse último caso uma hipótese a ser confirmada, algo próximo da "verdade", que "funciona como uma estratégia argumentativo-pragmática que permite ao locutor dizer algo ao interlocutor sem se comprometer pelo dito", como bem esclarece Nascimento e Silva (2012, p. 82).

Diferentemente dos asseverativos, ao escolher modalizadores quase-asseverativos, o locutor não se compromete ou não assume a responsabilidade pelo conteúdo da proposição, mas se resguarda de qualquer responsabilidade sobre a "verdade" ou falsidade da proposição. No dizer Castilho e Castilho (2002, p. 207), "através dos quase-asseverativos, avalia-se P como uma possibilidade epistêmica, decorrendo daqui uma baixa adesão do falante com respeito ao conteúdo do que está sendo verbalizado". Nota-se, portanto, que, nesse tipo de modalizador, o falante/locutor assume uma posição menos comprometedora, evitando marcar um posicionamento absoluto sobre o conteúdo da proposição.

Castilho e Castilho (2002) listam alguns exemplos em que os modalizadores quaseasseverativos marcam esse movimento subjetivo do locutor sobre o conteúdo de seu dizer: en acho, eu suponbo, é provável que P. No corpus investigado pelos referidos pesquisadores, foram 
constatados os seguintes modalizadores quase-asseverativos: talvez, assim, possivelmente, provavelmente e eventualmente. Seguem algumas ocorrências desses modalizadores constatados na pesquisa de Castilho e Castilho (2002, p. 227):

(61) o fiscal gosta muito... assim... de presentes.

(62) agora outro tipo de escola que talvez não tenha esse objetivo

(63) mas realmente a cadeia de supermercados aqui é de Recife provavelmente é superior a qualquer uma do país

(64) eventualmente eventualmente as linhas eróticas... e religiosas se cruzam

(65) e possivelmente passe essa fase

Diante dessas cinco ocorrências, Castilho e Castilho (2002) desenvolvem uma análise apontando a diferença de graus nos modalizadores quase-asseverativos. Nas ocorrências em (61) e (63) temos uma incerteza menor por parte do locutor - isso é intensificado com o verbo no indicativo. Já em (62) e (65), temos um grau maior de incerteza por parte do locutor, e o uso do verbo no subjuntivo confirma isso.

Compartilhando dessa perspectiva, Nascimento e Silva (2012, p. 82) analisam o seguinte enunciado: provavelmente não haverá aula hoje (grifo dos autores). Conforme esses estudiosos, "o conteúdo é apresentado como uma crença: o falante acredita que não haverá aula, mas não se compromete com a veracidade do que afirma". Nesse enunciado, a possibilidade epistêmica é materializada linguisticamente por meio do modalizador provavelmente.

Com relação ao aspecto argumentativo expresso por meio do modalizador, os referidos autores explicam que ele funciona eximindo o locutor da responsabilidade pelo enunciado, já que ele é apresentado como uma possível "verdade" e, ao mesmo tempo, permite ao locutor dizer algo ao seu interlocutor sem se comprometer com o dito.

\section{Aspectos metodológicos da pesquisa}

Neste artigo apresentamos dados da nossa tese, na qual trabalhamos com um corpus composto de 22 entrevistas de seleção de emprego gravadas em áudio durante o processo de seleção de professores para os cursos técnicos de Logística, Radiologia e Vigilância em Saúde, em um Centro Universitário do Estado do Rio Grande do Norte, na cidade de Natal - RN. A transcrição do corpus foi realizada com base no Projeto de Estudo da Norma Urbana Linguística Culta (PROJETO NURC).

Como nos propomos a discutir o funcionamento semântico-argumentativo da modalização epistêmica quase-asseverativa na construção argumentativa do gênero entrevista de seleção de emprego, fazemos uso do método de pesquisa qualitativa. De acordo com Marconi e Lakatos (2010, p. 213), "[...] a metodologia qualitativa preocupa-se em analisar e interpretar aspectos mais profundos, descrevendo a complexidade do comportamento humano". Assume ainda caráter descritivo, de base interpretativista, uma vez que descreve e analisa os fenômenos pesquisados (os modalizadores discursivos presentes no corpus), à luz do referencial teórico adotado, considerando, especialmente, os procedimentos analíticos e a classificação dos modalizadores discursivos apresentados por Nascimento e Silva (2012).

A fim de facilitar a leitura e a identificação dos modalizadores materializados, os trechos selecionados para análise estão destacados em itálico. E as formas modalizadoras, em itálico e negrito. $\mathrm{Na}$ análise, os recortes aparecem codificados. Essa codificação, realizada por ocasião da catalogação do corpus inclui o tipo de modalizador, a entrevista de seleção de emprego da qual extraímos o modalizador e as linhas transcritas da entrevista. Por exemplo, na codificação MEQA03 - EE01 - Linhas 21-31, a sigla MEQA03 corresponde ao Modalizador Epistêmico Quase-Asseverativo 03. Essa numeração - 03 - corresponde à sequência dos modalizadores 
encontrados e tabulados no corpus da pesquisa original. Já a sigla EE01 corresponde à Entrevista de Seleção de Emprego 01, conforme a ordem atribuída a cada entrevista coletada. E Linhas 21$31 \mathrm{diz}$ respeito às linhas da entrevista transcrita. O entrevistador (L1) e o entrevistado (L2). Por sua vez, o nome do Centro Universitário no qual realizamos a coleta do nosso corpus não será revelado, tendo em vista o compromisso que assumimos junto ao Conselho de Ética. Assim, usaremos o nome fictício denominado de Unixy.

Ainda, quanto ao corpus, a entrevista de seleção de emprego é um gênero discursivo oral, produzido com mais frequência no universo empresarial, e que tem a função de coletar informações a respeito de um postulante a uma vaga de emprego. Assim, é um dos gêneros utilizados no processo de recrutamento de pessoal das instituições empresariais, fortemente marcado pela assimetria entre os participantes da interação (entrevistador e entrevistado), conforme assinala Adelino (2016).

\section{Análise e discussão dos resultados}

Nas análises empreendidas, a modalização epistêmica quase-asseverativa é marcada em pontos da entrevista em que o locutor considera o conteúdo da proposição quase certo ou como uma hipótese a ser confirmada e por isso não se responsabiliza pelo valor de "verdade" da proposição.

\section{MEQA01-EE01-Linhas 17-19}

L1 mas... en já vejo por outro lado... acho que tem que ter sim... tem a necessidade... é um mundo que tá crescendo muito... uma área que está crescendo muito...

No trecho MEQA01, o enunciado aparece em primeira pessoa e coloca L1 na posição de sujeito com autonomia para responder pela instituição, e esse ganha espaço para registrar sua opinião a respeito da inclusão da disciplina de Radiologia Veterinária na estrutura curricular do curso de Radiologia. Evitando fazer asseverações e, assim, enunciando a expressão acho que (= é possível), L1 apresenta pouco comprometimento com o que diz, já que expressa seus argumentos como possíveis e não como certos.

Com a intenção de preservar a sua face, ou porque não quer se comprometer com o dito, L1 faz atenuações, que manifestam a sua opinião, e o seu discurso passa a constituir um enunciado possível de ocorrer ou não. Por isso emprega, estrategicamente, a expressão acho que para não se comprometer totalmente com o dito (NASCIMENTO; SILVA, 2012).

É importante ressaltar que existe a possibilidade de substituir acho que por outro verbo epistêmico, por exemplo, (considero/penso) mantendo, dessa forma, o mesmo sentido do enunciado, ou seja, indica uma opinião de natureza quase-asseverativa, simbolizando um baixo nível de adesão ao conteúdo proposicional.

Ademais, o efeito argumentativo nesse enunciado ocorre com a estratégia de proteção de face por parte de L1, ou seja, é possível perceber que L1 se protege, indicando que se trata de uma opinião particular que pode não ser compartilhada por outros, sendo possível diferentes modos de pensar. Assim, a modalização, nesse enunciado, constitui, então, uma estratégia argumentativa com vistas à atenuação do ato de fala no qual L1 se isenta da responsabilidade pelo dito.

\section{MEQA03-EE01-Linhas 73-76}

[...] L1 no caso... podemos antecipar e colocaria... um exemplo... colocaria os dias que o senhor disse... os dias flexíveis que o senhor possa estar aqui (...)

L2 até porque o nosso semestre lá vai acabar na primeira semana de dezembro... 
A modalização epistêmica nesse enunciado está marcada pela forma verbal podemos assim como pela palavra flexível. Através dessas expressões, L1 constrói um argumento pautado na possibilidade de organizar os horários de aula de L2 nos dias em que ele possa estar na instituição. Percebemos que L1 acredita nessa possibilidade, mas não se compromete com isso, pois não quer ou não pode assumir que vai realmente organizar os horários de L2 conforme a sua disponibilidade; por isso antecipa uma possível solução em forma de hipótese que dependerá de confirmação e que é marcada pelos modalizadores epistêmicos quase-asseverativos podemos e flexível, ambos usados como sinônimos da expressão "possível".

Observamos também que essa hipótese é baseada em uma perspectiva futura, ou seja, L1 não pode verificá-la no presente, até porque depende também da disponibilidade de L2 para fazer uma projeção do quadro de horários. Assim, o emprego dos modalizadores epistêmicos quase-asseverativos, nesse enunciado, expressa a atitude de L1 ao avaliar em termos de possibilidade o que poderá acontecer com o horário de L2.

Ao utilizar esse recurso estrategicamente, L1 se exime da responsabilidade e cria como efeito de sentido a atenuação do conteúdo do seu enunciado, evidenciando um baixo grau de adesão ao dito, de modo que não se compromete totalmente com o caráter de certeza ou verdade do conteúdo, ou seja, L1 não assegura a L2 que vai encaixar os horários para atender a sua disponibilidade de tempo, mas deixa implícita essa possibilidade.

De forma aparentemente intencional, L1 não faz uma asseveração, mas qualifica o dito como um compromisso epistêmico hipotético. Portanto, trata-se de uma possibilidade epistêmica, pois L1 está dizendo que é possível "antecipar". Não está dando, nem pedindo permissão, mas apresentando alternativas para tentar resolver o horário de L2 e, por isso, utiliza a modalização quase-asseverativa (NASCIMENTO; SILVA, 2012), uma vez que o conteúdo da proposição é apresentado como uma crença, como uma hipótese a ser confirmada, que funciona como uma estratégia argumentativo-pragmática que permite ao locutor dizer algo ao interlocutor sem se comprometer pelo dito.

Vale ressaltar que a palavra flexível é um adjetivo avaliativo, mas nesse contexto adquire um caráter quase-asseverativo. Por essa razão possui dupla função: modalizador avaliativo e modalizador quase-asseverativo.

\section{MEQA09- EE01-Linhas 134-139}

L1 dependendo dependendo de como podemos nos organizar né? podemos the atender... nós temos um sistema que ele faz essa essa locação do professor em determinado horário... tal dia ele pode... tal dia ele não pode... podemos organizar isso... MAS depois que tá feito não tem como mexer não... aí fica mais difícil... mas podemos ver umas soluções de dias espero que não bata... se pode ver isso aí...

No trecho MEQA09, L1 inicialmente argumenta sobre a possibilidade de organizar o horário de L2 já que este ministra aula em outra instituição. Constatamos que o caráter de possibilidade fica evidente em todo o enunciado uma vez que L1 não afirma que irá adequar os horários que L2 tem disponíveis para assumir a disciplina de Radiologia na escola técnica da Unixy. Apenas apresenta possíveis soluções, "podemos nos organizar", demonstra interesse em encontrar uma forma de adequação dos horários, chega a criar uma expectativa de que vai resolver essa questão ao comentar: "espero que não bata... se pode ver isso aî", na crença de que não vai ocorrer choque de horários, porém não se compromete totalmente com o conteúdo do enunciado. Isso fica marcado no enunciado principalmente por meio do uso do verbo "poder" (grifo nosso) que aqui assume esse caráter quase-asseverativo em todo o discurso de L1. Ou seja, L1 recorre a esse tipo de modalizador, (CASTILHO; CASTILHO, 2002), para avaliar o conteúdo da proposição como uma possibilidade, decorrendo daqui o efeito de sentido de baixa adesão de L1 com o dito, comprovando assim a visão dos autores supracitados. Percebemos, entretanto, que o emprego desses modalizadores sinalizam, de forma eficaz, que há muitas chances de L1 
conseguir encontrar uma forma de organizar os horários de L2, caso este seja aprovado na seleção para assumir a disciplina de Radiologia Veterinária.

Observamos, entretanto, que a palavra podemos apresenta dupla função nesse enunciado, a função de modalizador epistêmico quase-asseverativo e a função de modalizador epistêmico habilitativo uma vez que expressa também uma habilidade, uma capacidade de L1 de organizar os horários para atender a necessidade de L2, no entanto, sobressai, no contexto pragmático em que foi enunciado, o caráter quase-asseverativo.

MEQA16- EE03- Linhas 20-22

[...] L2 só que o Senac de repente tem uma demanda muito GRANde... mas... de repente a demanda diminui entendeu? então... há a necessidade do chefe de familia sair né?

Esse trecho da EE03 representa o argumento de L2 a respeito da quantidade de turmas de outra instituição na qual ele também atua como professor. Podemos observar que L2 faz uma avaliação da demanda de turmas ao utilizar a expressão de repente, ou seja, às vezes há uma demanda muito grande, porém de repente, ou outras vezes, essa demanda diminui. Dito de outra forma, L2 quer argumentar que não pode contar que sempre terá turmas nessa outra instituição em que ele desenvolve atividades docentes e para isso constrói seu argumento com base em relativizações. Portanto, a palavra de repente é um modalizador epistêmico quaseasseverativo, uma vez que adquire a função da expressão "às vezes", ou seja, é sinônima dessa expressão, nesse enunciado.

Assim, L2 faz uso da modalização epistêmica quase-asseverativa em destaque para criar um efeito de sentido de descomprometimento com o SENAC, ao mesmo tempo em que se coloca disponível para assumir novos compromissos com a instituição de cuja seleção ele está participando. A avaliação epistêmica marcada nesse enunciado apresenta uma relação com a ausência de certeza. Dessa forma, avalia a proposição, "de repente tem uma demanda muito grande", como algo incerto, ou seja, não é sempre que ele dispõe de turmas para ministrar aula no SENAC, por isso revela baixo grau de adesão ao conteúdo proposicional.

\section{MEQA23- EE03- Linhas 62-65}

[...] L1 só não tem a data o mês específico mas provavelmente no início do semestre de dois mil e quinz̧... e LA a gente pretende explorar outros horários... mas atualmente é à TARde e é AQUI... por isso eu quero que você fale da tua disponibilidade pra gente poder adequar...

O posicionamento de L1 no trecho MEQA23 é manifestado através de três modalizadores epistêmicos quase-asseverativos que evidenciam um grau parcial de adesão e comprometimento com o que diz. Esse recurso imprime a subjetividade do locutor, que assume com menor força o seu discurso, o que constitui uma estratégia para a construção da sua argumentação a respeito da indefinição de uma data e de um mês para a mudança do curso técnico de Logística para a nova unidade da instituição.

Dessa forma, apresenta o enunciado como provável por meio do advérbio provavelmente com a pretensão - pretende - de ampliar os horários do curso na nova unidade e, por isso, L1 deseja saber a disponibilidade de L2 para poder verificar a adequação dos horários. Trata-se de um emprego modal do futuro em que L1 presume com base em certas possibilidades, a saber, a da transferência do curso para um novo prédio, a exploração de outros horários nesse novo prédio e, por último, a disponibilidade de L2 para poder averiguar se este realmente terá condições de assumir turmas em qualquer horário que venha a ser ofertado futuramente. O emprego dessas formas, portanto, com caráter prospectivo, futuro, constitui um recurso usado por L1 para modalizar seu enunciado, de forma estratégica, visando marcar certo distanciamento em relação à certeza de que tudo que ele argumentou realmente irá ocorrer. Por isso, utiliza a modalização epistêmica quase-asseverativa, na terminologia de Castilho e Castilho 
(2002), posto que não faz uma asseveração, com efeito, qualifica seu compromisso com L2 como uma hipótese.

\section{MEQA32- EE05-Linhas 50-55}

L2 [...] eu faço ela dividida em três etapas... venho pra parte de exposição normal powerpoint... venho pra etapa depois dos trabalhos em grupo onde você faz todo mundo interagir... e depois das questões dos trabalhos você vai pra uma outra parte isso aí dependendo da carga horária... você pode fažer uma... e não em outra... e depois a gente comę̧a a distribuir sobre o aprendizado de cada um...

No trecho MEQA32, L2 discorre sobre os procedimentos que ele adota para organizar metodologicamente as suas disciplinas. L2 segue apresentando a sua metodologia de trabalho, mas em determinado momento, ele condiciona tal método à carga horária da disciplina. Ou seja, após argumentar sobre as três etapas adotadas - aula expositiva, trabalhos em grupo e verificação do aprendizado individual -, L2 diz que essas etapas podem ser aplicadas em algumas disciplinas, no entanto vai depender da carga horária. Assim, a possibilidade epistêmica se materializa linguisticamente nesse enunciado por meio da forma verbal pode $=e ́$ possivel utilizada para assinalar que não é sempre que L2 adota a mesma estratégia de trabalho assinala no enunciado, pois a adoção desse procedimento está condicionada à carga horária da disciplina. Ao utilizar esse modalizador, L2 se exime da responsabilidade de uma asserção, da afirmação de um fato e cria como efeito de sentido a atenuação do conteúdo do seu enunciado, uma vez que não se compromete totalmente com o dito. De maneira aparentemente intencional, L2 não revela a estratégia pedagógica padrão que utiliza em sua prática e, com isso, apresenta baixo grau de adesão ao seu próprio discurso.

\section{MEQA97- EE17-Linhas 74-76}

L2 eu acredito que sim... é trazer a economia pra o dia a dia... porque na verdade... a economia está no dia a dia... né? na sua familia... no orçamento de casa... na economia doméstica... então está no dia a dia...

Nesse trecho MEQA97 da EE17, L2 responde ao questionamento de L1 a respeito das estratégias de abordagens dos conteúdos da disciplina de economia para os alunos do curso técnico em Logística, tendo em vista ser um curso de curta duração e que recebe alunos com pouca base de conhecimento nessa área. Ao apresentar o seu ponto de vista, L2 defende que a economia faz parte do dia a dia das pessoas e por isso acredita que pode partir de exemplos práticos (orçamento de casa) e trabalhar em sala de aula questões de economia doméstica, para desmistificar o paradigma de que essa é uma disciplina difícil de ser ministrada com alunos de outras áreas do conhecimento.

Assim, L2 constrói o seu ponto de vista em forma de possibilidade epistêmica, que se materializa por meio da forma verbal acredito que cujo sentido externado nesse enunciado é o da crença, L2, portanto, não se compromete totalmente com o conteúdo da proposição, sinalizando que pode lecionar a disciplina de economia associando as discussões para questões mais rotineiras. L2 acredita na veracidade do que diz, mas não pode se comprometer com essa veracidade. Casos como estes já foram discutidos por diversos estudiosos da linguística, dentre eles podemos citar Castilho e Castilho (2002) e Nascimento e Silva (2012), que os denominaram de possibilidade epistêmica.

\section{MEQA122- EE22-Linhas 80-86}

L2 eu... eu geralmente planejo pra o semestre inteiro... certo? eu considero quantas aulas eu tenho por semana e:: eu planejo semana a semana... é:: muita gente pode dizer... a.: é muita coisa... mas não é:: porque a gente senta de uma vez... e tem o contato com aquilo de uma vez só... é.: então é... eu penso... sei lá... isso equivale... a.: geralmente... a.: vinte semanas... dezenove semanas... dezoito semanas... algo do tipo né? 
então... eu já faço o planejamento já pra o semestre inteiro... pensando pensando na continuidade do curso (...)

O trecho MEQA122 apresenta o ponto de vista de L2 a respeito do planejamento de aula. L2 inicia a sua fala explicando que na maioria das vezes costuma planejar as aulas para todo o semestre. Para não se comprometer com o conteúdo da proposição, faz uso do advérbio de frequência geralmente, visando deixar claro que essa prática não se aplica sempre em todas as suas turmas. Em seguida, faz um comentário sobre uma possível visão contrária a essa prática vinda de outros professores, usando a forma verbal pode, que aqui nesse enunciado exerce um sentido hipotético, uma vez que L2 não pode afirmar com certeza o que outros docentes dirão sobre os procedimentos adotados para desenvolver o planejamento pedagógico das suas aulas.

Dando sequência ao seu discurso, L2 mais uma vez faz uso do advérbio de frequência geralmente, para exemplificar que leva em consideração o número de semanas letivas do semestre quando vai elaborar o planejamento e isso ele faz visualizando a "continuidade do curso", podemos considerar, portanto, que a modalização epistêmica quase-asseverativa nesse trecho é materializada linguisticamente pelos modalizadores geralmente e pode. Esses modalizadores funcionam, ao mesmo tempo, como proteção de face, construindo, assim, um efeito argumentativo na interação entre interlocutores.

No nosso corpus, constatamos um total de 123 modalizadores dessa categoria. Essa alta incidência revela que, em determinados momentos da entrevista de seleção de emprego, os locutores estrategicamente escolhem não se comprometer totalmente com o conteúdo da proposição uma vez que dependem de outras questões que fazem parte do processo de seleção, tais como: perfil mais adequado para o cargo, remuneração, disponibilidade horário, entre outras.

Dessa forma, os locutores não se comprometem ou não assumem totalmente a responsabilidade pelo conteúdo da proposição. Sendo assim, a função desse subtipo de modalização no enunciado é de certa forma, isentar os locutores da responsabilidade sobre o que enunciam, conforme revelam os trechos analisados.

\section{CONSIDERAÇÕES FINAIS}

Neste artigo, focamos, sobretudo na modalização epistêmica quase-asseverativa que foi utilizada como recurso linguístico pelos locutores para orientar os argumentos na constituição do gênero entrevistas de seleção de emprego, gênero este que faz parte do universo empresarial e é utilizado, principalmente, por profissionais da área de Recursos Humanos para aprofundar questões relacionadas às competências e habilidades de candidatos a vaga de emprego, em processos de recrutamento e seleção de pessoal. Situamos nossa pesquisa nos postulados da Semântica Argumentativa, mais especificamente nos estudos sobre a Modalização Discursiva; articulados com os princípios da Teoria da Argumentação na Língua.

Tendo como objetivo discutir o funcionamento semântico-argumentativo da modalização epistêmica quase-asseverativa na construção argumentativa do gênero entrevista de seleção de emprego. De modo mais específico, procuramos desvendar (i) que recursos linguísticos instauram a modalização quase-asseverativa em entrevistas de seleção de emprego; e (ii) como esses recursos funcionam estrategicamente para gerar orientação argumentativa durante o processo interativo no gênero em estudo.

$\mathrm{Na}$ análise empreendida, constatamos que ao fazer uso desse subtipo de modalização epistêmica, o entrevistado e o entrevistador demonstram certo distanciamento em relação ao que apresentam em seus discursos. Percebemos que esse distanciamento fica marcado pela atenuação impressa no conteúdo da proposição, pela relativização da força da asserção e também pela isenção da responsabilidade com o dito. Ao usar essas estratégias, os locutores não se comprometem com o conteúdo enunciado e assim, apresentam a proposição em forma de hipótese que depende de confirmação. 
Encontramos ocorrências significativas deste tipo de modalizador no corpus investigado, materializados principalmente pelas seguintes expressões: "acho que", "podemos", não pode, pode, "flexiveis", "espero que", "de repente", "provavelmente", "pretende", "acredito que" e "geralmente". Esses modalizadores revelam, no gênero estudado, uma avaliação feita pelos locutores em termos de chances, de probabilidade do conteúdo enunciado se realizar. O efeito de sentido que se percebe, portanto, é o da atenuação do conteúdo proposicional, resultando comprometimento parcial dos locutores em relação ao que enunciam.

Essa estratégia argumentativa se faz presente nos relatos dos entrevistados (L2), principalmente quando estes apresentam argumentos a respeito dos seguintes tópicos: domínio da área à qual estava concorrendo à vaga de professor; possibilidade de encaixar horários; cuidados com a saúde; perfil do aluno; didática que pretende utilizar; capacidade para lidar com conflitos em sala de aula; escolha pela carreira docente; oferta de disciplinas nas outras universidades; possibilidade de contribuir com a formação dos alunos; conteúdos trabalhados na área de atuação; papel do professor em sala de aula; gosto pela docência; habilidade para lidar com os alunos; disponibilidade de tempo para assumir disciplinas na instituição recrutadora; qualificação profissional; possibilidade de assumir outras disciplinas; solicitação de informação a respeito das demais fases da seleção; conhecimento da matriz curricular do curso e planejamento de aula. Essas são as principais situações em que os entrevistados fazem uso do modalizador epistêmico quase-asseverativo.

Já nos relatos proferidos pelos entrevistadores (L1), percebemos que estes fazem uso dos modalizadores epistêmicos quase-asseverativos principalmente para discorrer sobre os seguintes assuntos: inclusão de determinadas disciplinas na estrutura curricular do curso; possibilidade de ajustar horários; resolução de conflitos entre os alunos; competência do professor quanto ao planejamento de aula; contribuição do professor para com a formação dos alunos; transferência dos cursos técnicos para outra unidade da Unixy; possibilidade de explorar outros horários para os cursos técnicos; possibilidade de progressão funcional na Unixy e experiência profissional do entrevistado.

Os achados da nossa pesquisa, portanto, ajudam a sustentar o postulado de que a argumentação, inerente à língua, mobiliza diferentes recursos semântico-discursivos e que esses recursos variam de um gênero do discurso para outro, dadas as funções de cada um e as esferas nas quais estão inseridos. As análises empreendidas vêm corroborar as conclusões postulas pelo LASPRAT - Laboratório Semântico-Pragmático de Texto da Universidade Federal da Paraíba -, ao qual este estudo se filia.

\section{REFERÊNCIAS}

ADELINO, F. J. S. Gênero entrevista de seleção: uma discussão teórica sob a perspectiva bakhtiniana. In: 25 Jornada Nacional do GELNE, 2014, Natal. Anais da XXV Jornada Nacional do GELNE. Natal: EDUFRN, 2014. p. 640-641.

.A modalização avaliativa no gênero relatório de estágio. In: XVII Congresso Internacional da ALFAL, 2014, João Pessoa. Estudos Linguísticos e Filológicos. Adaltech, 2014. p. 128-128.

.Na trilha dos modalizadores: perscrutando os jogos argumentativos no gênero entrevista de seleção de emprego. Tese (Doutorado). 332f. Universidade Federal da Paraíba. João Pessoa, 2016.

.A modalização avaliativa no gênero entrevista de seleção de emprego: estratégia semântico-argumentativa. In: I ELLIN: Encontro de Letras do Litoral Norte da Paraíba Língua, 
Literatura e Ensino: Diálogos Necessários, 2017, Mamanguape. I ELLIN: Encontro de Letras do Litoral Norte da Paraíba Língua, Literatura e Ensino: Diálogos Necessários. João Pessoa: Editara UFPB, 2017. v. 1. p. 17-29.

ADELINO, F. J. S.; NASCIMENTO, E. P. Gênero acadêmico: um estudo dos relatórios de estágio supervisionado produzidos no curso de Secretariado Executivo da UFPB. In: III Encontro Nacional Acadêmico de Secretariado Executivo. ENASEC, 2013, João Pessoa. O conhecimento científico e as novas tecnologias em Secretariado: relevância e impacto social. João Pessoa: Ideia, 2013. p. 265-380.

A modalização deôntica no gênero entrevista de emprego: estratégia semânticoargumentativa. In: Revista Diálogo das Letras, Rio Grande do Norte, v. 6, n. 2, jul -dez. 2017, p. 460-480.

Gêneros discursivos: Um olhar sobre a entrevista de seleção de emprego sob a perspectiva de Bakhtin. In: REVISTA DE GESTÃO E SECRETARIADO, São Paulo, v. 8, n. 2, mai -ago. 2017, p. 107-227.

.A orientação argumentativa dos modalizadores avaliativos. In: EID\&A - Revista Eletrônica de Estudos Integrados em Discurso e Argumentação, Bahia, n. 13, jan -jun. 2017, p. $18-35$.

.A expressão da modalização epistêmica asseverativa no gênero entrevista de seleção de emprego. In: XXVI Jornada do Grupo de Estudos Linguísticos do Nordeste, 2016, Recife. Anais eletrônicos da XXVI Jornada do Grupo de Estudos Linguísticos do Nordeste. Recife: Pipa Comunicações, 2016. p. 755-756.

CERVONI, J. A Enunciação. São Paulo: Ática, 1989.

CASTILHO, A.T.; CASTILHO, C. M. M de. Advérbios Modalizadores. In: ILARI, R. (Org.). Gramática do Português Falado. 2. ed. Campinas, SP: Editora da UNICAMP, 2002.

DUCROT, O. Provar e dizer: linguagem e lógica. São Paulo: Global Editora, 1981. .O dizer e o dito. Trad. Eduardo Guimarães. Campinas, São Paulo, Pontes, 1987.

Polifonia e argumentação: Conferencía del SeminárioTeoria de la Argumentación y Analisis del Discurso. Cali, Universidad del Valle, 1988.

ESPÍNDOLA, L. C. A entrevista: um olhar argumentativo. João Pessoa: EDUFPB, 2004.

KOCH, I. G. V. A inter-ação pela linguagem. 10 ed. São Paulo: Contexto, 2010.

Argumentação e Linguagem. 13. ed. São Paulo: Cortez, 2011.

LYONS, J. Semantics. Cambridge: Cambridge University Press, 1977.

MARCONI, M. A. ; LAKATOS, E. M. Metodologia do trabalho cientifico: procedimentos básicos, bibliografia, projeto e relatório, publicações e trabalhos científicos. São Paulo: Atlas, 2011. 
NASCIMENTO, E. P. do. Jogando com as vozes do outro: a polifonia - recurso modalizador - na notícia jornalística. Tese (Doutorado). Universidade Federal da Paraíba. João Pessoa: UFPB, 2005.

Jogando com as vozes do outro: argumentação na notícia jornalística. João Pessoa: Editora Universitária da UFPB, 2009.

Gênero do Universo Oficial/Empresarial: para além dos Manuais de Redação. In: Revista de Gestão e Secretariado, São Paulo, v. 1, n. 2, jul -dez. 2010, p. 127-147.

.A modalização deôntica e suas peculiaridades semântico-pragmáticas. In: Revista Fórum Linguístico. Florianopolis, v.7, n.1, jan-jun, 2010, p. 30-45.

.;SILVA, J. M. da. O fenômeno da Modalização. In: NASCIMENTO, E. P. do (Org.). A redação comercial oficial: estratégias semântico-discursivas em gêneros formulaicos. João Pessoa, Editora Universitária/UFPB, 2012.

NEVES, M. H. de M. Texto e Gramática. 3ª ed. São Paulo. Contexto, 2011.

PALMER, F. R. Moodandmodality. Cambridge: Cambridge University Press, 2001.

Submetido em 11/05/2018

Aceito em 18/11/2018 